\title{
DNA barcoding and genomics reveal Perizoma barrassoi Zahm, Cieslak \& Hausmann, 2006 as new for the fauna of Central Europe (Lepidoptera, Geometridae, Larentiinae)
}

\author{
Axel Hausmann $^{1}$, Peter Huemer ${ }^{2}$, Kyung Min LeE $^{3}$, Marko Mutanen ${ }^{3}$ \\ 1 SNSB - Bavarian State Collection of Zoology (Zoologische Staatssammlung), Munich, Münchhausenstr. 21, D-81247 \\ Munich, Germany, hausmann.a@snsb.de (corresponding author) \\ 2 Sammlungs- und Forschungszentrum, Tiroler Landesmuseen Betriebsgesellschaft m.b.H., Krajnc-Straße 1, 6060 Hall \\ in Tirol, Austria, p.huemer@tiroler-landesmuseen.at \\ 3 Ecology and Genetics Research Unit, P.O.Box 3000,FI-90014 University of Oulu, Finland; kyungmin.lee@oulu.fi, \\ marko.mutanen@oulu.fi,kyungmin.lee@oulu.fi
}

http://zoobank.org/7669F4FC-EB0C-4EB7-A0F4-8BDD14D3EF6F

Received 22 September 2020; accepted 11 December 2020; published: 16 February 2021

Subject Editor: Sven Erlacher.

\begin{abstract}
Perizoma barrassoi Zahm, Cieslak \& Hausmann, 2006, previously considered a central Italian endemic, shows a much wider distribution with additional records from the Alps and the Pyrenees, in partial sympatry with its sister species, Perizoma incultaria (Herrich-Schäffer, 1848) which is widespread in the Alps, Pyrenees, Carpathians and Dinaric mountains. The disruptive genetic patterns of both species involve the COI barcode gene as well as nuclear genomic data and are confirmed by correlated differential features in male and female genitalia. To fix nomenclatural stability a neotype is designated for $P$. incultaria.
\end{abstract}

\section{Introduction}

In his outstanding revision of European Perizomini and Eupitheciini, Mironov (2003) presented Perizoma incultaria (Herrich-Schäffer, 1848) as a species with montane distribution in the Alps, Pyrenees, Carpathians and western Balkan peninsula with comparatively narrow vertical distribution in the south (from $1500 \mathrm{~m}$ up to $2200 \mathrm{~m}$ ), but with a much wider range in the Alps (from $1000 \mathrm{~m}$ up to $3200 \mathrm{~m}$ ). Perizoma incultaria is known as the only European geometrid species which has leaf-mining first larval stages (on Primulaceae).

Three years after the publication of Mironov's monograph, Zahm et al. (2006) described a Central Italian sister species, $P$. barrassoi, based solely on a singleton male specimen from Maiella mountains that was designated as the holotype, and a female paratype from the same locality, the latter subsequently found out to be a misidentified, unusually small specimen of Colostygia aqueata (Hübner, 1813) (Müller et al. 2019). One additional specimen of P. barrassoi was collected by H. Rietz at high elevation on the Central Italian Monte Terminillo, just $100 \mathrm{~km}$ from the type locality, and could successfully be DNA barcoded, revealing a very large genetic divergence of $8.9 \%$ to $C$. incultaria (Müller et al. 2019). The reasons for attributing this Central Italian specimen to P. barrassoi are outlined below under the 'Remarks' to the Results section.

Müller et al. (2019) mentioned a genetic haplotype within the Alpine populations of 'Perizoma incultaria' which is very close to that of $P$. barrassoi (at just $1.1 \%$ distance) and thus far distant from the genetic cluster of $P$. incultaria. The distinctness of this second Alpine COI cluster compared 
with $P$. incultaria was confirmed by ddRAD sequencing involving hundreds of genome-wide nuclear loci (Mutanen et al. 2017; Müller et al. 2019). In this paper we present new insights from Sanger-sequenced DNA barcodes and from additional High-Throughput Sequencing (HTS) of the COI barcode gene fragment of material collected close to the type localities as well as from extended dissections. We show that $P$. barrassoi is much more widespread than originally thought.

\section{Material and methods}

The study is based on more than 250 specimens of Perizoma incultaria and P. barrassoi, including 46 dissections, 29 DNA barcodes and ddRAD-data for eight specimens. The material is housed at the following collections:

HNS Haus der Natur, Salzburg, Austria;

RCTM Research Collection Toni Mayr, Feldkirch, Austria;

TLMF Tiroler Landesmuseum Ferdinandeum, Innsbruck, Austria;

ZSM SNSB - Zoologische Staatssammlung München, Germany.

\section{Taxon delineation}

The taxa were delimited on the basis of combining data from various sources: morphology, bionomy (mainly phenology, partly vertical distribution) and DNA barcodes. The genitalia and the abdomens were prepared following methods described by Hardwick (1950). Morphological analyses were performed with a Wild microscope (308700), measurements were taken with a calibrated measuring eyepiece, slide photographs were taken with multilayer automontage technique (Helicon software) at a Leica microscope (DM2700M).

\section{DNA barcoding}

For the DNA barcoding analyses, one or two legs were removed from each dried specimen and transferred to lysis plates. DNA extraction, amplification, and sequencing of the barcode region of the mitochondrial cytochrome c oxidase I (COI) gene (658 base pairs) were carried out in the Canadian Centre for DNA Barcoding, Guelph, Ontario, Canada (CCDB), using standard high throughput protocols (Ivanova et al. 2006), those are described at CCDB (2020). Sequence divergences within and between species were calculated using the Kimura 2-parameter model (Kimura 1980) and the Neighbor-joining algorithm (Saitou and Nei 1987), as implemented in the Barcode of Life Data System (BOLD; Ratnasingham and Hebert 2007). High Throughput Sequencing (HTS) of old museum material was performed at the CCDB following the methodology presented by Prosser et al. (2016) and Speidel et al. (2015).

\section{ddRAD library preparation and bioinformatics}

We used DNA aliquots that were extracted at the Canadian Centre for DNA Barcoding (CCDB) following laboratory protocols used routinely in CCDB as explained in DeWaard et al. (2008). The quantity of genomic DNA (gDNA) extracts was checked using PicoGreen kit (Molecular Probes). To reach sufficient gDNA quantity and quality, whole genome amplification was performed using the REPLI-g Mini Kit (Qiagen) due to its low concentrations of gDNA in the original extracts. The ddRAD library was implemented following protocols described in Lee et al. (2018) with two exceptions: gDNA was 
digested with PstI and MspI and the size distribution and concentration of the pools was measured with Bioanalyzer (Agilent Technologies). The de-multiplexed fastq data are archived in the NCBI SRA: SRP155304. Raw paired-end reads were de-multiplexed with no mismatches tolerated using their unique barcode and adapter sequences using ipyrad v.0.7.23 (Eaton and Overcast 2016). All ipyrad defaults were used, with the following exceptions: the minimum depth at which majority rule base calls are made was set to 3 , the cluster threshold was set to 0.95 , the minimum number of samples with data for a given locus to be retained in the final dataset was set to 2 to 8 , and the assembly method was set to 'denovo' and 'reference' for independent testing. The 'denovo' method assembled sequences without any reference resources. The 'reference' assembly method mapped sequences to Operophtera brumata (Linnaeus, 1758) whole genome sequences (GenBank, GCA_001266575) with $B W A$ using the default bwa-mem setting (Li 2013) based on $95 \%$ of sequence similarity.

\section{Analyses of ddRAD data}

To infer maximum likelihood (ML) trees, we used RAxML v.8.2.0 (Stamatakis 2014) with bootstrap support estimated by a 1,000 replicates of rapid-bootstrap analysis from the GTR+GAMMA model. We visualised the resulting phylogeny using FigTree v.1.4.2 (Rambaut 2015). To investigate genetic variation between individuals, we inferred population clustering with admixture from SNP frequency data using STRUCTURE (Pritchard et al. 2000). We ran 10 independent analyses for each value of $K$, between 1 and 3 , each consisting of $50 \mathrm{~K}$ burnin generations and $500 \mathrm{~K}$ postburnin generations. Results were summarized and compared in CLUMPP (Jakobsson and Rosenberg 2007). The optimal $K$ value was inferred using StructureHarvester (Earl and VonHoldt 2012) according to the ad hoc $\Delta K$ statistics (Evanno et al. 2005). Genetic assignments were visualized using DISTRUCT (Rosenberg 2004).

\section{Examination of Wolbachia infection}

To check for the presence of bacterial parasite Wolbachia, we sequenced two markers, FstZ and Wsp, using primers and laboratory procedures of Ivanov et al. (2018).

\section{Results}

\section{Perizoma barrassoi Zahm, Cieslak \& Hausmann, 2006}

Perizoma barrassoi Zahm, Cieslak \& Hausmann, 2006: 95:31, figs 1a, b, 2a, b (Locus typicus: Italy, Abruzzo: Maiella Mts., Valle Cannella, Manzini-Hütte). Holotype male (coll. Zahm/ZSM, examined and dissected, DNA barcoding failed). Associated female paratype a misidentification of Colostygia aqueata (Hübner).

Material examined. Italy: Holotype male, central Italy, Abruzzo, Maiella, Valle Cannella, Manzini-Hütte, 2530 m, 23.vii.1988, leg. N. Zahm, coll. ZSM (gen.prp. ZSM G 20836; DNA barcode sample ID BC ZSM Lep 54528, 77874 (failures); 1 female, central Italy, Lazio, Rieti, Mt. Terminillo, 1800 m, 18.vii.2004, DNA barcode sample ID BC ZSM Lep 82927, gen.prp. ZSM G 15840; 2 males, Trentino, Adamello, Rifugio Mandrone, 2450 m, 26.vi.2014, leg. T. Mayr, DNA barcode sample ID TLMF Lep 25428 (RCTM); France: 1 male, France, Hautes Alpes, Pelvoux, [2000 m], 1.10.viii.1972, leg. L. Hinterholzer, gen.prp. ZSM G 21237 (ZSM); 1 male, France, Alpes Maritimes, Col des Champs, [2100 m], 5.vii.1931, [leg. C. Herbulot], gen.prp. ZSM G 21238 (ZSM); 1 female, France, Alpes Maritimes, Cayolle, 2100 m, 31.vii.1975, leg. Lukasch, gen.prp. ZSM G 21259 (ZSM); 1 female, France, Hautes Alpes, la Moutieres, 2100 m, 3. viii.1975, leg. Lukasch (ZSM); 1 female, France, Valloire, 1500 m, 31. vii.1954, leg. G. Bernardi (ZSM); 1 male, France, 
Pyrenees orientales, Porté, 1650-2100 m, 25.VI.-21. vii.1948, leg. H. de Toulgoet, gen.prp. ZSM G 14302 (ZSM); 1 female, France, Pyrenees orientales, Col de Puymorens, 1900 m, 10.vii.1975, leg. G. Behounek, gen.prp. ZSM G 21255 (ZSM); Germany: 1 female, Germany, Bavaria, Allgäu, Oberstdorf, Oytal, Oybach E Oytalhaus, 1036 m, 01.vi.2014, leg. D. Doczkal, DNA barcode sample ID BC ZSM Lep 86512, gen.prp. ZSM G 21249 (malaise trapping, ZSM); 2 males, Germany, Bavaria, Eschenlohe, [700 m], 12.vi.1977, leg. L. Hinterholzer, gen.prp. 21229 (ZSM); 3 females, Germany, Bavaria, Bergen, Weißachental, 700 m, 24.v.1980, leg. A. Beyerl (ZSM); Austria: 16 males and females, Austria, North Tyrol, Riedenberg / Landl, 800-900 m, 16.v-19.vi.1974-1979 leg. Scheuringer, Wolfsberger, gen.prp. ZSM G 21228, 21248 (ZSM); 1 male, Austria, northern Tyrol, Ötztaler Alps, Feichten, 1300 m, late May 1986, leg. E. Scheuringer, gen.prp. ZSM G 21233 (ZSM); 1 male, id., late May 1992 (ZSM); 1 female, id., early June 1983, gen.prp. ZSM G 21257 (ZSM); 1 female, id., leg. [coll.] Wolfsberger (ZSM); 2 males, Austria, North Tyrol, unterhalb Farst / Umhausen N, 1100 m, 10.iv.2017, leg. P. Huemer, DNA barcode sample ID TLMF Lep 22852, 22853 (TLMF); 1 male, id., 28.v.2013, DNA barcode sample ID TLMF Lep 12589; 1 male, Austria, East Tyrol, Matreier Tauerntal, Aussergschloess Umgebung, 1700 m, 14.vi.2013, leg. P. Huemer, DNA barcode sample ID TLMF Lep 13024 (TLMF).

External characters and abdomen (Fig. 1). See description in Müller et al. (2019). The newly attributed Alpine populations with wingspan of 17-21 mm in males, 19-22 $\mathrm{mm}$ in females. Ground colour whitish pale grey, silky shining. Wing pattern varying in a similar way as in the sister species $P$. incultaria, no constant and reliable differential feature in wing pattern and coloration was found that would allow discrimination between the two sibling species. Palpi short, length $0.5-0.7 \mathrm{~mm}$, hardly exceeding frons. Male antennae ciliate-setose, flagellum dorsally chequered grey and white.

Male genitalia $(n=7$; Figs 3-5). The genitalia of the newly attributed Alpine populations are well matched to those of the holotype, i.e. showing comparatively narrow valvae, ventral and dorsal margins approximately parallel, costa of valva narrow from base to apex, at apex narrowly tapering (cf. Müller et al. 2019). Anal tube strongly developed, spinulose at tip. Head of (fused) labides comparatively large. Aedeagus with five to nine small cornuti of $0.1 \mathrm{~mm}$ (basalmost) to $0.25 \mathrm{~mm}$ (distalmost), cornuti not dilated at base. Length of aedeagus $0.9-1.1 \mathrm{~mm}$.

Female genitalia $(\mathrm{n}=6$; Figs 9-11). The genitalia of the newly attributed Alpine populations are well matched to those of the central Italian female as figured in Müller et al. (2019). Apophyses fine, tapered at apices. Colliculum (in earlier publications referred to as 'ductus bursae' but homol-
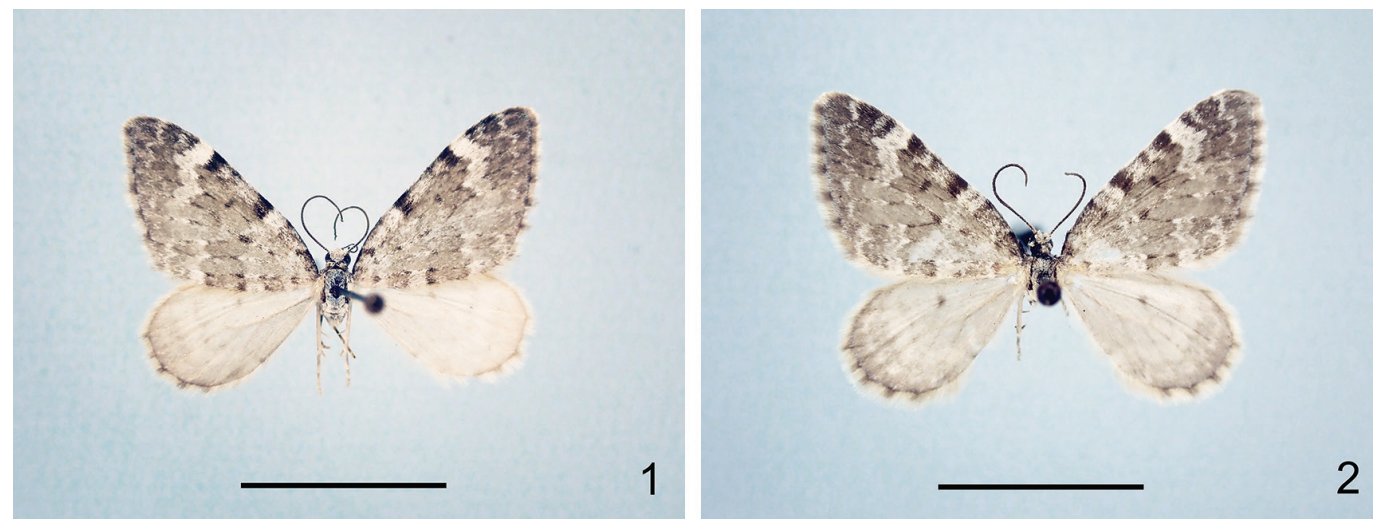

Figures 1, 2. Adults (females). 1. Perizoma barrassoi (Austria, Riedenberg); 2. Perizoma incultaria (Germany, Hirschberg). Scale bars: $1 \mathrm{~cm}$. 




Figures 3-8. Male genitalia. 3-5. Perizoma barrassoi (3. Austria, Riedenberg; 4. Germany: Eschenlohe; 5. France, Pyrenees, Porté); 6-8. Perizoma incultaria (6. Austria, Brandenberg; 7. Italy, Friuli, Altiplano Montasio; 8. Italy, southern Tyrol, Sulden). Scale bar: $1 \mathrm{~mm}$. 
ogy with colliculum postulated in Mironov 2003) elongate, length $0.37-0.5 \mathrm{~mm}$, in one specimen $0.6 \mathrm{~mm}$ ), parallel-sided almost over the whole length. Corpus bursae small, often globular. Scobinate signum small, round, lateral spinules weak, diameter $0.10-0.17 \mathrm{~mm}$.

Differential diagnosis. In external appearance (wing shape, wing coloration, pattern), the newly attributed populations of $P$. barrassoi from the Alps and the Pyrenees do not exhibit significant and constant differences from the sympatric $P$. incultaria. The latter differs in male genitalia $(\mathrm{n}=23$; Figs 6-8) with much broader costa of valva which is dilated towards apex and ending in a small, sclerotized, beak-shaped process and bearing a conspicuous setal tuft. Aedeagus with stout cornuti (5-7), the distalmost being the largest, usually curved and dilated at base. Female genitalia of $P$. incultaria $(\mathrm{n}=10$; Figs 12-14) are similar to those of $P$. barrassoi, but in the former the colliculum is longer $(0.6-0.7 \mathrm{~mm})$, signum larger, more elongate, often triangular, length $0.13-0.3 \mathrm{~mm}$, lateral spinules stout.

Distribution. Recorded in central Italy (locus typicus: Maiella mountains; Mt. Terminillo), Pyrenees, French Alps, and in a section of the central part of the Alps with records, so far, restricted to eastern and northern Tyrol (Austria) and to southernmost Bavaria (Germany), as a sympatric, sibling species of $P$. incultaria (see examined material and genetic data). Furthermore an isolated occurrence was detected in northern Italy (Adamello).

Phenology. Univoltine, the two central Italian records are from mid-July and late July, in the Pyrenees and French Alps the species flies from early July to early August. The remaining records from the Alps, however, refer to much earlier dates, from mid-April to late May, the single specimen from eastern Tyrol in mid-June and specimens from northern Italy in late June. Therefore, when occurring sympatrically, $P$. barrassoi flies earlier than $P$. incultaria whose Alpine populations are usually on the wing from early June to early August.

Biology. The larval stages are unknown. Larvae of the sister species P. incultaria feed on Primulaceae (first stages), later instars also on Saxifragaceae. Representatives of both plant families are abundant at the collecting sites of $P$. barrassoi.

Habitat. Montane. Collected on karstic slopes at $2500 \mathrm{~m}$ in the Maiella and $1800 \mathrm{~m}$ on Mt. Terminillo. In French Alps and Pyrenees from $1500 \mathrm{~m}$ up to $2100 \mathrm{~m}$ and in northern Italy (Adamello) occurring at $2450 \mathrm{~m}$. In the Bavarian and Austrian Alps collected from much lower elevations in valleys from $1000 \mathrm{~m}$ up to $1300 \mathrm{~m}$ (Bavaria; northern Tyrol) $(\mathrm{n}=29)$ with only one specimen from eastern Tyrol recorded at $1700 \mathrm{~m}$, while the vertical distribution of sympatric $P$. incultaria ranges from $1700 \mathrm{~m}$ up to $3200 \mathrm{~m}$, with very few exceptions.

Genetic data (DNA barcodes and nuclear genomic data). The specimen from Mt. Terminillo was DNA barcoded with an HTS approach, resulting in a 658 bp sequence including an 89 bp n-gap. BIN: BOLD:ACJ5976 ( $\mathrm{n}=1$ from central Italy). Six specimens from Austria, south-western Bavaria and northern Italy are BIN-sharing, at a distance of only $1.1 \%$ from central Italian $P$. barrassoi. The genetic divergence from $P$. incultaria is strongly correlated with the differential features in genitalia and bionomic traits (see above). Nearest species: P. incultaria $(8.5 \% ; \mathrm{n}=19$ from Germany, Austria and northern Italy; BIN BOLD:AAF5044). The distinctness of Alpine P. barrassoi and $P$. incultaria at species level was confirmed by ddRAD-sequencing involving nuclear loci (Mutanen et al. 2017). Two specimens of $P$. incultaria from the type locality near Gastein (Austria, Salzburg) could be sequenced, using the HTS approach for old museum material and revealed to belong to BIN BOLD:AAF5044, confirming the suggestion of species identity as P. incultaria as inferred from the comparatively high elevation (1800-2000 m). 

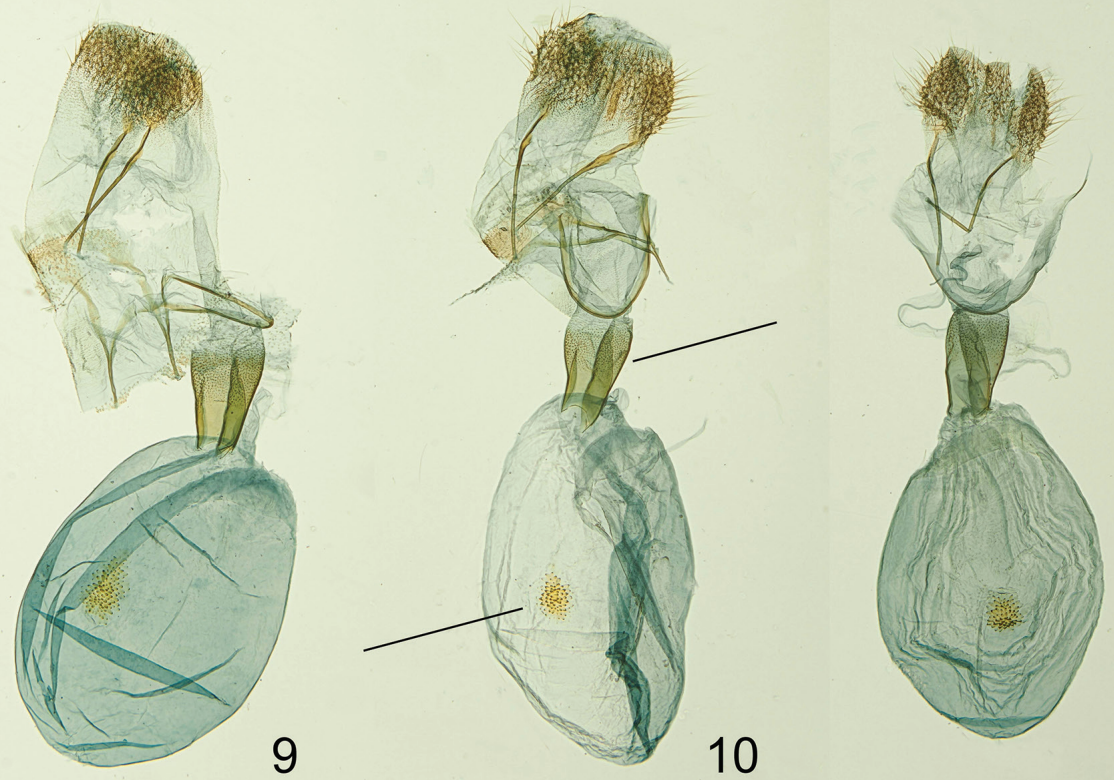

11

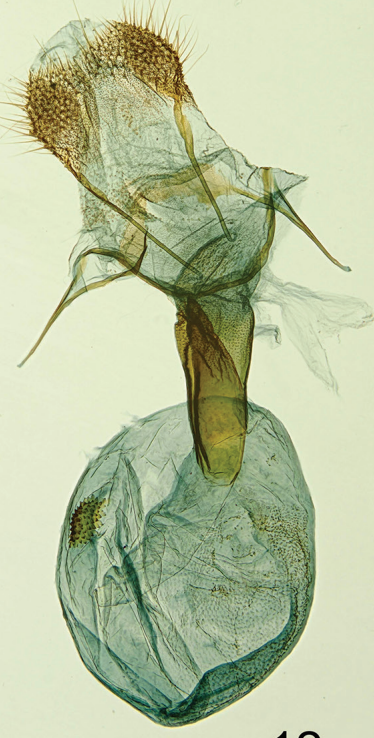

12
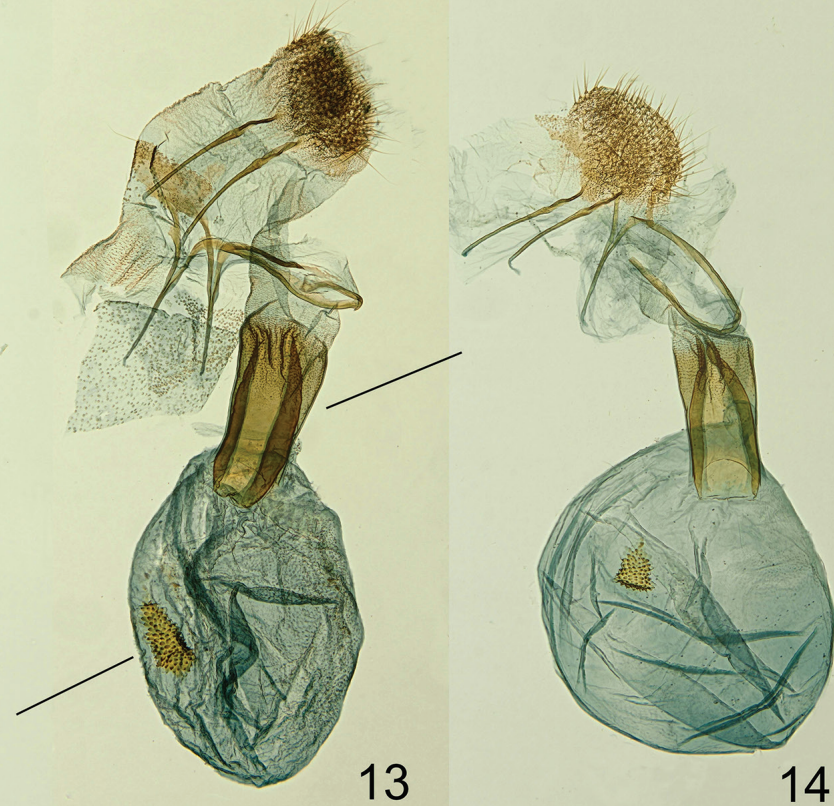

Figures 9-14. Female genitalia. 9-11. Perizoma barrassoi (9. Austria, Feichten; 10. French Alps: Cayolle; 11. France, Pyrenees, Col de Puymorens); 12-14. Perizoma incultaria (12. Germany, Hochfelln; 13. Germany, Koblat; 14. Italy, Mt. Grappa). Scale bar: $1 \mathrm{~mm}$. 




Figures 15-20. Details of female genitalia: Signum. 15-17. Perizoma barrassoi (same slides as Figures 9-11); 18-20. Perizoma incultaria (same slides as Figures 12-14). Scale bar: $0.1 \mathrm{~mm}$.

Data exploration and phylogenetic analyses based on SNP data. We generated a genome-wide set of genetic clusters from 8 individuals of Perizoma incultaria using ddRAD sequencing, and used this data set to perform phylogenetic analyses. We obtained 1.54 million reads per individual on average, of which $84.8 \%$ were retained after stringent quality filtering steps. After filtering and clustering at 95\% sequence similarity using 'de novo' assembly method, we recovered 1,042 putative orthologues shared across more than three samples, for a total length of 193,994 base pairs (Fig. 21A). These data include 1,678 SNPs, of which 200 are parsimony informative. For the 'reference' assembly, an average of 1,298 reads per sample was mapped to the Operophtera brumata genome, while an average of 107,289 reads per sample remained unmapped. Because the reference species is only distantly related to Perizoma, the sample 'BC ZSM Lep 84546' was dropped out in the reference assembly due to the lack of mapped reads to the reference genome. After filtering, 222 clusters per sample were obtained, with 45.13 per sample for cluster depth on average. The final dataset from the reference assembly consisted of 50 recovered loci across more 
than three individuals (Fig. 21B). Phylogenetic analysis using the concatenated ddRAD dataset produced robust support for the relationship between the individuals (Fig. 21). The ML tree based on the reference assembly produced a remarkably congruent tree with the tree of de novo assembly. In both ML trees, the two revealed lineages correspond to cluster A ( $P$. incultaria, marked with green) and cluster B (P. barrassoi, marked with orange) that was supported by $100 \%$ bootstrap support values. STRUCTURE also identified two discrete clusters (Fig. 21). Only one of the eight examined samples ('TLMF Lep 00264') was Wolbachia infected.

\section{Discussion}

The shape and pattern of the wings of the barcoded, Central Italian female collected at Monte Terminillo (just $100 \mathrm{~km}$ from the type locality of $P$. barrassoi in the central Apennines) clearly showed it to belong to the Perizoma incultaria/barrassoi species complex although the large geographical distance of $500 \mathrm{~km}$ from the nearest Alpine populations of $P$. incultaria and the scarcity of high alpine habitats in the northern Apennines supported the initial hypothesis of conspecificity of that Central Italian specimen with P. barrassoi. This hypothesis was corroborated by the fact that the male genitalia of the holotype from the Maiella mountains agree perfectly with the male genitalia of one of the Alpine DNA barcode clusters, the latter corresponding to the barcoded central Italian female.

(a) ddRAD data, de novo assembly

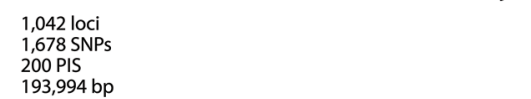

$$
193,994 \mathrm{bp}
$$



(b) ddRAD data, reference assembly

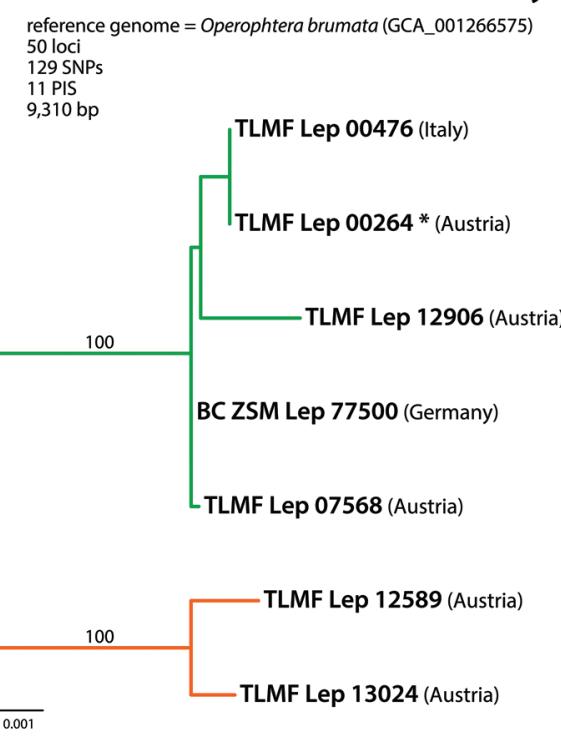

Figure 21. Maximum likelihood trees inferred from the ddRAD data matrices based on (a.) de novo assembly and (b.) reference assembly method against Operophtera brumata genome (GCA_001266575). Bootstrap support values are indicated above the branches and only the values $>50 \%$ are shown. The barplot shows the assignments of individuals into two genetic clusters, the green clusters referring to Perizoma incultaria, the orange clusters to $P$. barrassoi. Each bar represents one individual and colors represent the proportion of the individuals that belong to each of the genetic cluster. Samples infected with Wolbachia are marked with an asterisk. 
Larentia incultaria was described from two males and a single female collected in the Alps (Herrich-Schäffer 1843-1855). In the original description two collectors are mentioned, Kindermann, without further details to his material, and Koch, with Gastein (Salzburg, Austria) as collecting locality. The type material is presumed destroyed (not traced in the museums in London and Berlin). Since this species cannot be separated externally from $P$. barrassoi and both taxa may co-occur in the area of Gastein, we, in accordance with ICZN (1999), designate a neotype to preserve nomenclatural stability. The male specimen was collected at the type locality of $P$. incultaria and it is labelled as follows: [Austria], Salzburg, Bad Hofgastein, Schlossalm, 2000 m, 06.viii.1975, leg. G. Embacher; DNA Barcode ID: BC ZSM Lep 103434. The Neotype was successfully DNA barcoded with a HTS approach to a $658 \mathrm{bp}(200 \mathrm{n})$ fragment, unambiguously clustering with $P$. incultaria.

The discovery of a cryptic species of Geometridae in the Alps and Pyrenees comes as a surprise, although, recently, a similar case has been discovered in the genus Perizoma when P. juracolaria (Wehrli, 1919) was recognized as a cryptic species differing from its sister species, $P$. obsoletata (Herrich-Schäffer, 1838) in morphology and DNA barcodes (Bérard et al. 2005; Müller et al. 2019). The zoogeographical pattern of species pair $P$. obsoletata / P . juracolaria is reminiscent of that of $P$. incultaria / P. barrassoi with P. juracolaria being distributed in the Alps, southern France, in the Apennines and in the Balkan Peninsula (Müller et al. 1919). In the herewith presented case of $P$. barrassoi, the advantages of a comprehensive DNA barcode screening of local faunas are demonstrated once again (cf. Huemer and Hebert 2011; Huemer and Mutanen 2012; Huemer et al. 2013). Hardly anyone would have come up with the idea to study series of the widespread P. incultaria morphologically. Only the discovery of two highly divergent DNA barcode clusters was the trigger for such an exploration.

Perizoma barrassoi shows, according to current data, an unusual distribution pattern which is presumed to be due to a patchy recording. The distinctly isolated sub-areas in parts of the Alps and in the Pyrenees as well as in the central Apennines seem implausible when compared with the zoogeographical patterns of other geometrids inhabiting alpine and sub-alpine habitats, e.g. the above mentioned $P$. juracolaria. There is a large probability that $P$. barrassoi has still unrecorded relic populations in the northern Apennines and it will show a wider distribution in the western Alps including Switzerland, Piedmont and Valle d'Aosta. In particular, the early flight time, which starts shortly after the snowmelt, as well as the morphological similarity with $P$. incultaria are obvious reasons for the possibility that the species has simply been overlooked in many places.

\section{Acknowledgements}

We are very grateful to the staff at the Canadian Centre for DNA Barcoding for sequence analysis. Paul D.N. Hebert, Evgeny Zakharov and many other colleagues of the Barcode of Life project (Centre for Biodiversity Genomics, Guelph, Canada) contributed to the success of this study. The data management \& analysis system BOLD was provided by Sujeevan Ratnasingham (CBG, Guelph). PH is indebted to the Promotion of Educational Policies, University and Research Department of the Autonomous Province of Bolzano - South Tyrol for funds to the projects "Genetische Artabgrenzung ausgewählter arktoalpiner und boreomontaner Tiere Südtirols" and "Erstellung einer DNA-Barcode-Bibliothek der Schmetterlinge des zentralen Alpenraumes (Süd-, Nord- und Osttirol)". We also thank Lauri Kaila, Jörg Gelbrecht and Hossein Rajaei for giving valuable comments to the manuscript. Gernot Embacher and Patrick Gros (Haus der Natur Salzburg, Austria) kindly helped 
with material of $P$. incultaria from the type locality, Toni Mayr (Feldkirch, Austria) with Italian samples of $P$. barrassoi. We thank Laura Törmälä for the invaluable help in the molecular laboratory and CSC - IT Centre for Science, Finland for computational resources. This work was supported by the Academy of Finland (grant number 277984) to MM and the Kvantum Institute to KML.

\section{References}

Bérard B, Tautel C, Mazel R (2005) Perizoma juracolaria Wehrli, 1919 comb. n., bona species Perizoma obsoletata avilaria Reisser, 1936 stat. rev. (Lepidoptera, Geometridae, Larentiinae). Revue de 1'association Roussillonnaise d‘Entomologie (R.A.R.E.) 14(2): 54-67.

CCDB [Canadian Centre for DNA Barcoding] (2020) Description of DNA barcode protocols, http://www. dnabarcoding.ca/pa/ge/research/protocols [accessed 1 August 2020]

DeWaard JR, Ivanova NV, Hajibabaei M, Hebert PDN (2008) Assembling DNA barcodes: analytical protocols. In: Martin C (Ed.) Methods in molecular biology: environmental genetics. Totowa, NJ, Humana Press, 275-294. https://doi.org/10.1007/978-1-59745-548-0_15

Earl DA, VonHoldt BM (2012) STRUCTURE HARVESTER: a website and program for visualizing STRUCTURE output and implementing the Evanno method. Conservation Genetics Resources 4: 359-361. https:// doi.org/10.1007/s12686-011-9548-7

Eaton DAR, Overcast I (2016) ipyrad: interactive assembly and analysis of RADseq data sets. http://ipyrad. readthedocs.io/ [accessed 1 August 2020]

Evanno G, Regnaut S, Goudet J(2005) Detecting the number of clusters of individuals using the software structure: a simulation study. Molecular Ecology 14: 2611-2620. https://doi.org/10.1111/j.1365-294X.2005.02553.x

Hardwick DF (1950) Preparation of slide mounts of lepidopterous genitalia. Canadian Entomologist 82: 231235. https://doi.org/10.4039/Ent82231-11

Herrich-Schäffer GAW [,1847“] (1843-1855) Systematische Bearbeitung der Schmetterlinge von Europa, zugleich als Text, Revision und Supplement zu Jakob Hübner's Sammlung europäischer Schmetterlinge. Dritter Band. Die Spanner G. J. Manz, Regensburg, 184 pp. [Index 1-34, pl. 1-90] https://doi.org/10.5962/ bhl.title.67734

Huemer P, Elsner G, Karsholt O (2013) Review of the Eulamprotes wilkella species group based on morphology and DNA barcodes, with descriptions of new taxa (Lepidoptera, Gelechiidae). Zootaxa 3746: 69-100. https://doi.org/10.11646/zootaxa.3746.1.3

Huemer P, Hebert PDN (2011) Cryptic diversity and phylogeography of high alpine Sattleria - a case study combining DNA barcodes and morphology (Lepidoptera: Gelechiidae). Zootaxa 2981: 1-22. https://doi. org/10.11646/zootaxa.2981.1.1

Huemer P, Mutanen M (2012) Taxonomy of spatially disjunct alpine Teleiopsis albifemorella s. lat. (Lepidoptera: Gelechiidae) revealed by molecular data and morphology - how many species are there? Zootaxa 3580: 1-23. https://doi.org/10.11646/zootaxa.3580.1.1

ICZN (1999) International Code of Zoological Nomenclature. $4^{\text {th }}$ edn. International Trust for Zoological Nomenclature, The Natural History Museum London, $306 \mathrm{pp}$.

Ivanov V, Lee KM, Mutanen M (2018) Mitonuclear discordance in wolf spiders: Genomic evidence for species integrity and introgression. Molecular Ecology 27: 1681-1695. https://doi.org/10.1111/mec.14564

Ivanova NV, deWaard JR, Hebert, PDN (2006) An inexpensive, automation-friendly protocol for recovering high-quality DNA. Molecular Ecology Notes 6: 998-1002. https://doi.org/10.1111/j.14718286.2006.01428.x

Jakobsson M, Rosenberg NA (2007) CLUMPP: a cluster matching and permutation program for dealing with label switching and multimodality in analysis of population structure. Bioinformatics 23: 1801-1806. https://doi.org/10.1093/bioinformatics/btm233 
Kimura M (1980) A simple method for estimating evolutionary rate of base substitution through comparative studies of nucleotide sequences. Journal of Molecular Evolution 16: 111-120. https://doi.org/10.1007/ BF01731581

Lee KM, Kivelä SM, Ivanov V, Hausmann A, Kaila L, Wahlberg N, Mutanen M (2018) Information dropout patterns in restriction site associated DNA phylogenomics and a comparison with multilocus Sanger data in a species-rich moth genus. Systematic Biology 67: 925-939. https://doi.org/10.1093/sysbio/syy029

Li H (2013) Aligning sequence reads, clone sequences and assembly contigs with BWA-MEM. arXiv 1303: 3997.

Mironov V (2003) Larentinae II. In: Hausmann A (Ed.) The Geometrid Moths of Europe, vol. 4. Apollo Books, Stenstrup, 464 pp.

Müller B, Erlacher S, Hausmann A, Rajaei H, Sihvonen P, Skou P (2019) Ennominae II. In: Hausmann A, Sihvonen P, Rajaei H (Eds) The Geometrid Moths of Europe, vol. 6. Brill, Leiden, 906 pp. https://doi. org/10.1163/9789004387485

Mutanen M, Lee KM, Hausmann A, Hebert PDN, Huemer P, Lopez Vaamonde C, Rougerie R, Segerer A (2017) A genomic perspective on deep DNA barcode splits in European Lepidoptera. Abstracts $20^{\text {th }}$ European Congress of Lepidopterology, Podgora, Croatia: 70.

Pritchard JK, Stephens M, Donnelly P (2000) Inference of population structure using multilocus genotype data. Genetics 155: 945-959.

Prosser SWJ, deWaard JR, Miller SE, Hebert PDN (2016) DNA barcodes from century-old type specimens using next-generation sequencing. Molecular Ecology Resources 16: 487-497. https://doi.org/10.1111/17550998.12474

Rambaut A (2015) FigTree, v1.4.2: Tree Figure Drawing Tool. Molecular evolution, phylogenetics and epidemiology. http://tree.bio.ed.ac.uk/software/figtree/ [accessed 1 August 2020]

Ratnasingham S, Hebert PDN (2007) BOLD: The Barcode of Life Data System (http://www.barcodinglife. org). Molecular Ecology Notes 7(3): 355-364. https://doi.org/10.1111/j.1471-8286.2007.01678.x

Rosenberg N (2004) DISTRUCT: a program for the graphical display of population structure. Molecular Ecology Notes 4: 137-138. https://doi.org/10.1046/j.1471-8286.2003.00566.x

Saitou N, Nei M (1987) The neighbor-joining method: a new method for reconstructing evolutionary trees. Molecular Biology and Evolution 4: 406-425.

Speidel W, Hausmann A, Müller GC, Kravchenko V, Mooser J, Witt TJ, Prosser S, Hebert PDN (2015) Taxonomy 2.0: next generation sequencing of old type specimens supports the description of two new species of the Lasiocampa decolorata group from Morocco (Lepidoptera: Lasiocampidae). Spixiana 3: 401-412. https://doi.org/10.11646/zootaxa.3999.3.5

Stamatakis A (2014) RAxML version 8: A tool for phylogenetic analysis and post-analysis of large phylogenies. Bioinformatics 30: 1312-1313. https://doi.org/10.1093/bioinformatics/btu033

Zahm N, Cieslak A, Hausmann A (2006) Perizoma barrassoi species nova aus den Abruzzen (Lepidoptera, Geometridae, Larentiinae). Mitteilungen der Münchner Entomologischen Gesellschaft 95: 31-35. 